\title{
Tetralogia de Fallot e sua repercussão na saúde bucal
}

\author{
Repercussion of tetralogy of Fallot on oral health
}

\section{Cristiane Meira Assunção', Tatiana Falleiros², Renato Cordeiro Gugisch ${ }^{3}$, Fabian Calixto Fraiz ${ }^{4}$, Estela Maris Losso ${ }^{5}$}

\section{RESUMO}

Objetivo: Relatar o caso de um paciente com tetralogia de Fallot e sua condição bucal.

Descrição do caso: Paciente do gênero masculino atendido no Curso de Especialização em Odontopediatria da Escola de Aperfeiçoamento Profissional da Associação Brasileira de Odontologia da seção Paraná dos cinco aos sete anos de idade. O exame clínico intrabucal inicial revelou quadro de cárie severa da infância. Durante o acompanhamento, verificou-se a erupção dos primeiros molares permanentes com a presença de defeitos de desenvolvimento de esmalte e perda de estrutura dental. À anamnese, a mãe relatou que o paciente foi portador de tetralogia de Fallot e que a cirurgia corretora foi realizada com um ano e 11 meses de idade.

Comentários: A formação do esmalte dental dos primeiros molares permanentes ocorre a partir do primeiro mês de vida e é finalizada entre dois e quatro anos de idade. Neste caso, tal etapa coincidiu com o período anterior à cirurgia para correção da tetralogia de Fallot, fato que pode ter interferido negativamente no processo de mineralização dos primeiros molares permanentes. Os defeitos de desenvolvimento do esmalte podem levar a perda de estrutura dental, favorecendo o aparecimento da cárie dentária. Dessa forma, o odontopediatra deve realizar um diagnóstico precoce dessas alterações e intervir preventivamente para evitar a perda de tais dentes. Uma anamnese bem detalhada e a maior interação entre pediatras e odontopediatras podem proporcionar melhor acompanhamento de crianças com fatores de risco para apresentar defeitos de desenvolvimento do esmalte dentário.

Palavras-chave: tetralogia de Fallot; esmalte dentário; saúde bucal; criança.

\section{ABSTRACT}

Objective: To report a case of a child with tetralogy of Fallot and his oral conditions.

Case description: A male patient was assisted at the Pediatric Dentristry Specialization Course of the Brazilian Dentistry Association in the State of Paraná, Brazil, from five to seven years old. At the first intrabucal examination, the child presented a severe caries disease. During their treatment, enamel developmental defects were detected in the first permanent molar tooth, with loss of enamel structure. His mother reported that the patient had a surgical correction of tetralogy of Fallot cardiac malformation when he was 23 months old.

Comments: The enamel development of the first molar starts in the first month of life and ends around two to four years old. In this patient, the period of mineralization of the first molar was coincident with the period prior to the surgical correction of the cardiac problem. Probably, the development of dental enamel was impaired by the systemic repercussion of this congenital anomaly. Enamel developmental defects can present loss of dental structure, increasing the risk of caries. Therefore, the pediatric dentists should diagnose dental enamel developmental defects early, in order to prevent serious damages to the teeth. A detailed anamnesis and a good interaction between pediatricians and pediatric dentists will provide a better follow-up of children at risk of having dental enamel developmental defects.

Key-words: tetralogy of Fallot; dental enamel; oral health; child.
${ }^{1}$ Especialista em Odontopediatria pela Escola de Aperfeiçoamento Profissional da Associação Brasileira de Odontologia, seção Paraná, (EAP/ABOPR), Curitiba, PR, Brasil

${ }^{2}$ Especialista em Odontopediatria pela EAP/ABO-PR, Curitiba, PR, Brasil ${ }^{3}$ Doutor em Odontopediatria pela Faculdade de Odontologia da Universidade de São Paulo (FOUSP), e professor adjunto da Universidade Federal do Paraná (UFPR), Curitiba, PR, Brasil

${ }^{4}$ Doutor em Odontopediatria pela FOUSP, e professor-associado da UFPR, Curitiba, PR, Brasil

${ }^{5}$ Doutora em Odontopediatria pela FOUSP, e professora titular da Disciplina de Odontologia para a Infância do Centro Universitário Positivo, Curitiba, PR, Brasil
Endereço para correspondência:

Cristiane Meira Assunção

Rua Equador, 60 - Bacacheri

CEP 82.510-120 - Curitiba/PR

E-mail: crisassuncao@hotmail.com.

Recebido em: 15/8/2007

Aprovado em: 21/1/2008 


\section{Introdução}

A tetralogia de Fallot é uma cardiopatia congênita com quatro características principais: defeito do septo ventricular, obstrução na via de saída do ventricular direito, aorta em dextroposição e hipertrofia do ventrículo direito $^{(1)}$. É a cardiopatia congênita cianótica mais freqüente. Os defeitos anatômicos diminuem a quantidade de oxigênio no sangue, levando à cianose, policitemia e hipóxia. A hipóxia é encontrada com freqüência, predispondo os pacientes a acidentes cerebrovasculares. Quando não tratada, a maioria dos pacientes morre ainda na infância, sendo, portanto, indicada a cirurgia corretora o mais cedo possível, preferencialmente entre 18 e 24 meses de idade ${ }^{(2)}$.

A tetralogia de Fallot tem sido amplamente estudada na medicina há décadas, porém, as implicações na odontologia ainda são praticamente desconhecidas. Na literatura consultada, apenas um trabalho relatou a condição bucal de pacientes com tetralogia de Fallot. Tal relato de caso clínico descrevia os aspectos bucais de uma criança de quatro anos. Os tecidos moles apresentavam aspecto normal, mas existia grande destruição devido à doença cárie em quase todos os dentes decíduos. O tratamento odontológico foi realizado sob anestesia geral, e sendo feitas restaurações com cimento ionômero de vidro e exodontias. Não foi comentada, neste relato, a condição da dentição permanente ${ }^{(2)}$.

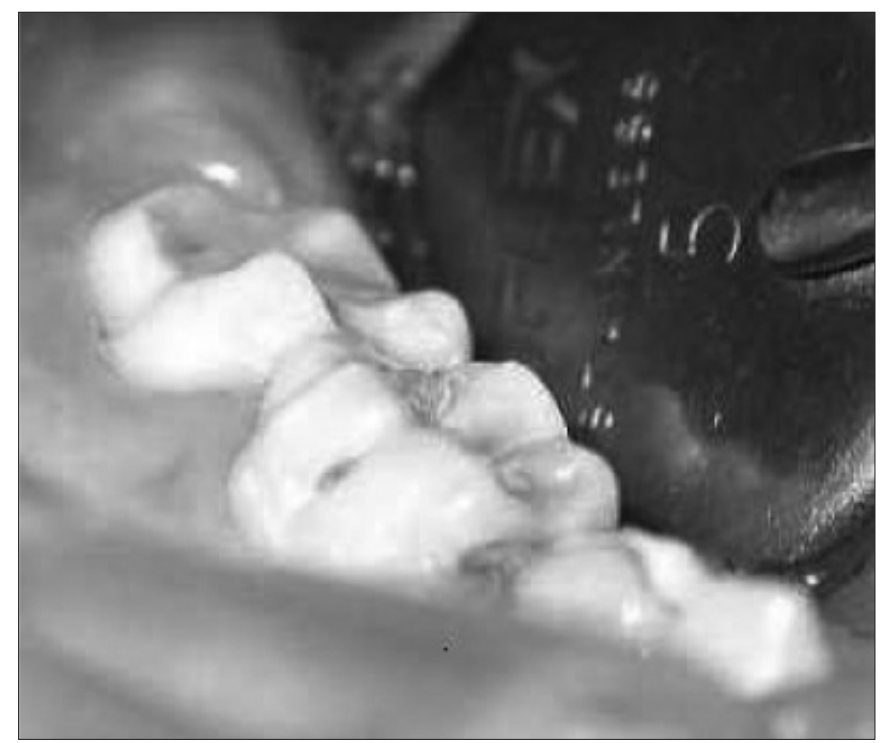

Figura 1 - Primeiro molar inferior direito semi-irrompido, já apresentando sinais de defeito de desenvolvimento de esmalte, com perda de estrutura
Neste contexto, o objetivo do presente trabalho foi relatar o caso de um paciente com tetralogia de Fallot e sua condição bucal.

\section{Descrição de caso}

Após o consentimento livre e esclarecido, foi realizada uma anamnese com a mãe da criança, sendo também utilizadas informações do prontuário odontológico do paciente e do relatório da avaliação psicopedagógica.

Tratava-se de paciente do gênero masculino, atendido no Curso de Especialização em Odontopediatria da Escola de Aperfeiçoamento Profissional da Associação Brasileira de Odontologia da seção Paraná aos cinco anos idade e acompanhado até os sete anos.

A anamnese revelou que a mãe não apresentou intercorrências durante a gestação da referida criança, que nasceu de parto cesáreo com $2.850 \mathrm{~kg} \mathrm{e} 51 \mathrm{~cm}$ de comprimento. Aos 12 dias de vida, foi internado inconsciente, sendo diagnosticada tetralogia de Fallot. A genitora refere que, no período que antecedeu a correção cirúrgica, a criança fez uso dos seguintes medicamentos: cloreto de potássio, digoxina, amoxacilina e furosemida. Com um ano e 11 meses de idade, foi realizada a correção da alteração cardíaca. Após a cirurgia, a criança apresentava algumas restrições para prática de exercícios e recebia profilaxia com antibióticos antes de qualquer procedimento que pudesse causar bacteremia. Além do acompanhamento clínico com cardiopediatra, também fazia sessões de fonoaudiologia e atendimento psicológico.

Ao primeiro exame clínico odontológico, com cinco anos de idade, apresentava dentição decídua e ausência dos incisivos centrais e laterais superiores, extraídos aos dois anos. O paciente possuía um quadro clínico compatível com o de cárie severa da infância, com lesões de cárie em praticamente todos os dentes. Foi iniciado o controle da doença cárie com adequação de meio bucal, que incluiu a selamento provisório das cavidades de cárie dentária, a fluorterapia e a orientação de higiene e de dieta.

Aos seis anos de idade, os molares permanentes iniciavam sua erupção e se evidenciava a presença de defeitos de desenvolvimento do esmalte (Figura 1). Os incisivos permanentes estavam hígidos e apenas no incisivo superior direito via-se pequena mancha amarelo-clara na região incisal. O primeiro molar permanente superior direito apresentava manchas hipocalcificadas amarelo-claro e perda de estrutura nos sulcos principais e da cúspide disto-vestibular, sendo restaurado com cimento de ionômero de vidro Ketac Molar ${ }^{\circledR}$. 
Nas consultas de controle, verificou-se a completa erupção dos outros primeiros molares permanentes, todos com defeitos de desenvolvimento de esmalte. Devido à perda de estrutura, os dentes foram restaurados com cimento de ionômero de vidro Ketac Molar ${ }^{\circledR}$ (Figura 2).

\section{Comentários}

Diante do caso relatado, dois aspectos podem ser ressaltados. O primeiro refere-se ao maior risco de aparecimento de cárie severa da infância em crianças com doenças sistêmicas. O segundo ponto refere-se à repercussão dessas doenças na dentição permanente, evidenciada por alterações durante a fase de mineralização dos dentes, ocasionando defeitos de desenvolvimento de esmalte.

No primeiro atendimento, o paciente apresentava cárie severa da infância, quadro semelhante ao descrito anteriormente na literatura ${ }^{(2)}$. Tal condição estaria relacionada a uma dieta infantilizada (uso prolongado e excessivo de mamadeira associado ao açúcar), freqüente em pacientes com problemas sistêmicos. Este fato ressalta a importância de um acompanhamento odontológico desde os primeiros anos de vida, principalmente em pacientes debilitados, que têm maior risco de apresentar a doença cárie, tanto pela dieta infantilizada quanto pelo uso crônico de medicamentos que contêm açúcar.

Dentes com defeitos de desenvolvimento de esmalte são comuns em crianças com doenças sistêmicas durante o período neonatal e em crianças prematuras ${ }^{(3)}$. Os dentes hipoplásicos e/ou hipocalcificados são mais suscetíveis a um maior acúmulo de placa bacteriana, podendo levar a uma progressão mais rápida da doença cárie. Além disso, tais dentes são mais sensíveis, dificultando a higiene bucal e favorecendo uma dieta mais pastosa.

Crianças com cardiopatias congênitas apresentam uma proporção maior de lesões de cárie não tratadas e uma porcentagem maior de defeitos de esmalte ${ }^{(4)}$, o que as torna de alto risco ao desenvolvimento da doença cárie ${ }^{(5)}$. Entre essas crianças, as que receberam por mais tempo digoxina ${ }^{\circledR}$ apresentaram um maior número de lesões de cárie ${ }^{(6)}$.

Problemas sistêmicos durante o período de formação do esmalte (amelogênese) podem afetar irreversivelmente os ameloblastos, causando defeitos na secreção ou mineralização da matriz de esmalte ${ }^{(7)}$. O processo de mineralização da coroa dentária dos primeiros molares permanentes tem seu início no primeiro mês de vida, sendo concluída entre os dois e quatro anos de idade ${ }^{(8)}$. No caso relatado, o período coincide com a cardiopatia não corrigida, uma vez que a cirurgia ocorreu quando a criança tinha um ano e 11 meses, podendo ter repercutido negativamente na formação deste tecido mineralizado.

Deve-se, portanto, diante de doenças sistêmicas na infância, acompanhar a erupção dos dentes permanentes, para que, caso haja hipocalcificações ou outros defeitos de desenvolvimento de esmalte, seja possível intervir precocemente, prevenindo o aparecimento de lesões de cárie e a perda de estrutura do esmalte hipocalcificado. Por outro lado, os incisivos iniciam sua mineralização mais tarde. A mancha em esmalte do incisivo central superior direito, no paciente aqui relatado, pode estar relacionada a uma lesão periapical do dente decíduo antecessor, extraído aos dois anos em decorrência da doença cárie.

Crianças com tetralogia de Fallot apresentam maior risco para a endocardite bacteriana. A presença de placa bacteriana e a gengivite podem aumentar o risco de crianças cardiopatas congênitas desenvolverem endocartite bacteriana ${ }^{(4)}$. Deve-se, portanto, ressaltar a importância das medidas preventivas, a educação em saúde bucal e a motivação do

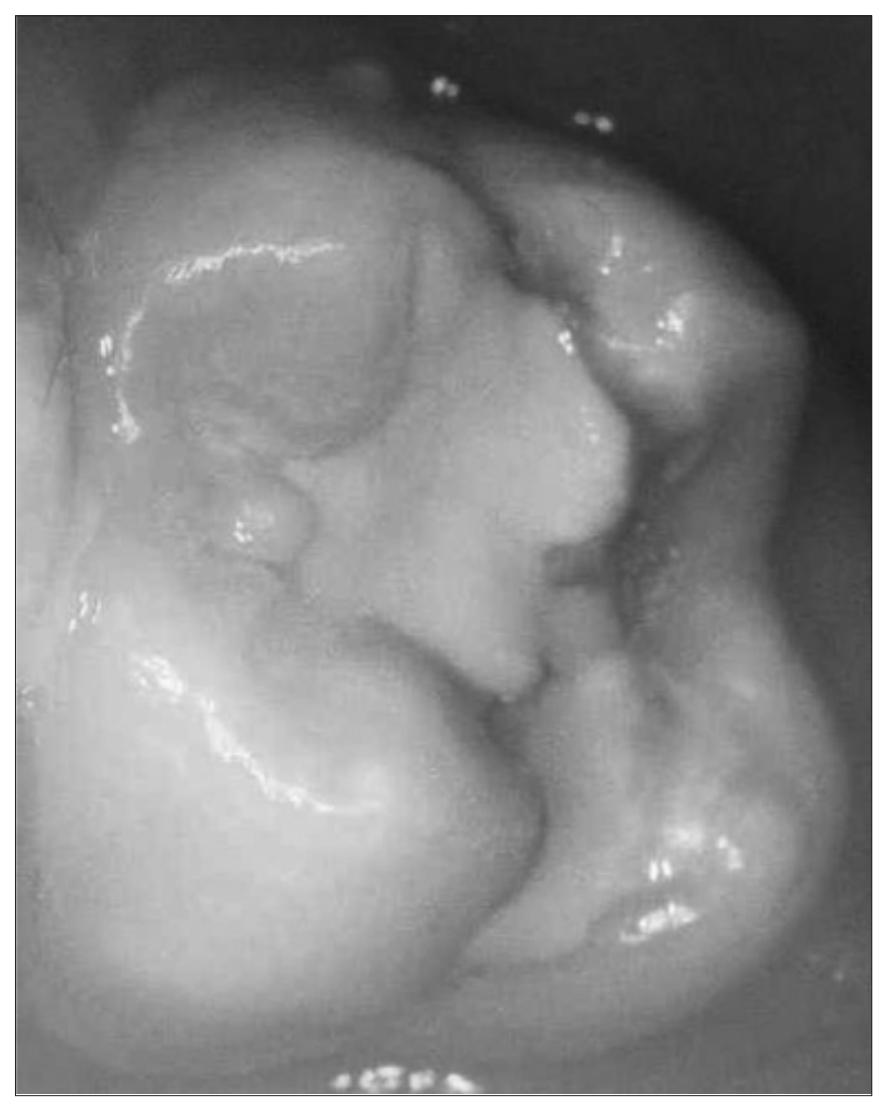

Figura 2 - Primeiro molar superior esquerdo restaurado com cimento de ionômero de vidro (Ketac Molar ${ }^{\circledR}$ ). Fotografia realizada na consulta de controle 
núcleo familiar. Assim, evitam-se procedimentos invasivos, os quais, no caso de pacientes com tetralogia de Fallot, sempre serão precedidos de profilaxia antibiótica ${ }^{(9)}$.

Diante do paciente relatado, pode-se concluir que crianças com problemas sistêmicos, mesmo em idade precoce, necessitam de maior atenção odontológica. Além disso, uma anamnese detalhada permite diagnóstico e tratamento adequados. Maior interação entre os médicos pediatras e odontopediatras proporcionará melhor acompanhamento da criança de risco para defeitos de esmalte e cárie e também possibilitará aos pais mais informações sobre a condição e as necessidades de seus filhos para o seu crescimento saudável. Deve-se trabalhar a prevenção odontológica o mais cedo possível para que tais crianças cresçam livres da doença cárie e periodontal, as quais podem ter importante repercussão sistêmica.

\section{Referências bibliográficas}

1. Pinsky WW, Arciniegas E. Tetralogy of Fallot. Pediatr Clin North Am 1990;31:179-92.

2. Spivack E. Tetralogy of Fallot: an overview, case report, and discussion of dental implications. Spec Care Dentist 2001;21:172-5.

3. Machado FC, Ribeiro RA. Defeito de esmalte e cárie dentária em crianças prematuras e/ou de baixo peso ao nascimento. Pesq Bras Odontoped Clin Integr 2004;4:243-7.

4. Franco E, Saunders CP, Roberts GJ, Suwanprasit A. Dental disease, caries related microflora and salivary IgA of children with severe congenital cardiac disease: an epidemiological and oral microbial survey. Pediatr Dent 1996;18:228-35.

5. Fernández de Preliasco V, Biondi AM, Oliver L. A comparison of the oral status of children with congenital heart diseases. Bol Assoc Argent Odontol Niños 2005;34:4-7.

6. Stecksén-Blicks C, Rydberg A, Nyman L, Asplund S, Svanberg C. Dental caries experience in children with congenital heart disease: a case-control study. Int J Paediatr Dent 2004;14:94-100.

7. Bessa CF. Fatores sistêmicos e locais associados a anomalias do esmalte dentário. Arq Odontol 2002;38:5-18.

8. de Moraes LC. Cronologia da mineralização dos incisivos e primeiros molares permanentes entre brasileiros da Região Sudeste [tese de doutorado]. São José dos Campos (SP): Unesp; 1974.

9. Balmer R, Bu'Lock FA. The experiences with oral health and dental prevention of children with congenital heart disease. Cardiol Young 2003;13:439-43. 